\title{
DNA damage induced by 7,12-dimethylbenz $[a]$ anthracene in the liver and the mammary gland of rats exposed to polycyclic aromatic hydrocarbon enzyme inducers during perinatal life
}

\author{
C.Bolognesi ${ }^{1,4}$, M.Parrini ${ }^{1,4}$, C.Aiello ${ }^{2,3}$ and L.Rossi ${ }^{2,3}$ \\ Toxicological Evaluation Unit, Laboratory of Chemical Carcinogenesis ${ }^{1}$ and \\ Laboratory of In Viw Carcinogenesis ${ }^{2}$, Institute of Clinical and \\ Experimental Oncology, School of Medicine, University of Genoa ${ }^{3}-$ \\ Instituto Nazionale per la Ricerca sul Cancto ${ }^{4}$, Viale Benedetto XV, \\ 10-Genova, Italy
}

The long-lasting modulating effect induced by the prenatal or neonatal exposure to phenobarbital (PB) and aroclor on the genotoxic activity of 7,12-dimethylbenz[a]anthracene (DMBA) in female Sprague-Dawley rats was studied. The effect was measured as DNA damage evaluated in the liver and in the mammary gland of 55-day-old animals, 4 and $24 \mathrm{~h}$ after an i.g. injection of $80 \mathrm{mg} / \mathrm{kg}$ of DMBA. PB was given per os, i.g. or in drinking water to pregnant females and by i.g. only to neonates or in adult progeny. Aroclor was injected i.g. in prenatal and in neonatal life, and a second dose was given in adult life. Under these experimental conditions it was shown that DNA damage kinetics caused by DMBA are modulated by exposure to $\mathrm{PB}$ and, to a minor extent, by aroclor. The amount and persistence of DNA damage were highest when PB was administered to neonates. An average 2-fold increase in the elution constants $(K)$ of DNA in the liver and the mammary gland was observed $4 \mathrm{~h}$ after DMBA treatment, as compared to uninduced animals. Repeated enzyme induction by $\mathrm{PB}$ seems to reduce DMBA genotoxicity, as shown by a decrease in DNA damage and persistence in the liver and mammary gland. The inducibility of the monooxygenase enzyme system in perinatal life favouring metabolic activation or inactivation of polycyclic aromatic hydrocarbons might be critical in determining individual susceptibility of adult progeny to chemical carcinogenesis by DMBA.

\section{Introduction}

Polycyclic aromatic hydrocarbons (PAH) are an ubiquitous class of environmental chemicals, many of which are known to be carcinogenic in animal models. The ability of PAH, such as 7,12-dimethylbenz[a] anthracene (DMBA), to induce mammary tumours in female rats is well documented (Huggins and Fukunishi, 1962; Dao, 1964; Russo et al., 1977; Huggins, 1979) Reports have shown that the induction of these neoplasms is related to the age of the animals at the time of carcinogen feeding (Huggins et al., 1961; Dao et al., 1964; Dao, 1969). In fact, one of the most important factors determining the sensitivity of the mammary gland to neoplastic stimuli is its stage of maturation at the time of exposure to the carcinogenic agent. With DMBA the maximum effect was observed in 55-day-old Sprague-Dawley females where up to $100 \%$ incidence of mammary tumours was observed (Dao, 1969). A direct relationship was demonstrated between the age at treatment, the binding of DMBA to DNA and the incidence of mammary tumours (Janss and Ben, 1978).

Many factors can potentially modulate the susceptibility of laboratory animals to tumour induction by PAH. Most relevant is the cytochrome-P450-dependent metabolism, a process known to activate PAH to metabolic derivatives exerting biological effects, such as cytotoxicity, DNA damage, mutagenesis and carcinogenesis (Di Giovanni and Jachen, 1980). The oxidative enzymes of the endoplasmic reticulum which metabolize PAH are low or barely detectable in rodents at earlier fetal stages and increase during the perinatal period of life (Gillette and Stripp, 1975; Doerjer et al., 1978; Pelkonen, 1980). In some rodent strains these enzyme activities may be increased by the transplacental exposure to enzyme inducers (Nebert and Gelboin, 1969; Nebert, 1973; Jefcoate, 1983). As a consequence, enhanced tumour initiation by PAH might occur in the offspring.

Our investigation was designed to evaluate DMBA-induced DNA damage in the mammary gland and in the liver of Sprague-Dawley female rats treated with $\mathrm{PAH}$ inducers during prenatal and neonatal life. The detection of an increased level of DNA damage in target tissues suggests that perinatal modulation of P450-dependent metabolism can have lasting effects in adult life.

\section{Materials and methods}

\section{Chemicals}

DMBA, phenobarbital (PB) and aroclor 1254 were obtained from Sigma Biochem (St Louis, MO, USA). 33258 Hoechst (2-[2-(4-hydroxyphenyl)-6-benzimidazole]-6-(1-methyl-4-piperazyl)-benzimidazole trihydrochloride) was from Farbwerke Hoechst (FRG). DMBA was suspended in corn oil. PB was dissolved in com oil or tap water and aroclor was suspended in com oil.

\section{Treatment and handling of the animals}

Pregnant Sprague-Dawley rats were purctased from Charles River (Como, Italy) and housed in a temperanure-controlled room $\left(22-23^{\circ} \mathrm{C}\right)$ under artificial lighting (12 h light). Standard pelleted diet (Italiana Mangimi, Milano, Italy) and drinking water were supplied ad libitur. The animals were divided in nine groups acoording to the scheme outlined in Table I. At the time of DMBA treatment there were 12 females per group: eight of them were given DMBA and four were left untreated. The compounds were given per os. In pregnant females treatment with PB was done i.g. ( $60 \mathrm{mg} / \mathrm{kg}$ body wt) or in drinking water $(0.5 \mathrm{mg} / \mathrm{kg}$ body wt) from days 14 to 20 of gestation, while aroclor was administered i.g. at a dose of $100 \mathrm{mg} / \mathrm{kg}$ body wt on days $14,16,18$ and 20 of pregnancy. Newbom were treated per i.g. from day 1 to 7 of age in two ways: daily with PB (60 mg/kg body wt) and one every other day with aroctor ( $100 \mathrm{mg} / \mathrm{kg}$ body wt). At 55 days of age females were treated i.g. with a single dose of DMBA $80 \mathrm{mg} / \mathrm{kg} \mathrm{b.w}$. At 24 and $72 h$ before DMBA treatment the animals of groups 3 and 5 were given a single i.g. dose of phenobarbital $(60 \mathrm{mg} / \mathrm{kg}$ body wt), while those of groups 6,7 and 8 received aroclor ( $\$ 00 \mathrm{mg} / \mathrm{kg}$ body wt).

\section{Preparation of crude nuclei}

Rats belonging to each group were sacrificed as follows: those which received DMBA were decapitated under slight narcosis and bled 4 and $24 \mathrm{~h}$ after treatment with carcinogen, the remaining untreated animals were sacrificed in the same way and used as controls. Mammary glands and livers were removed and processed to obtain crude nuclei. Tissues were handled at $0-4^{\circ} \mathrm{C}$. Briefly, the liver was minced and pressed through a stainless steel net in order to obtain cells stripped from adhering tissues. Crude nuclei were centrifuged at $50 \mathrm{~g}$ for $2 \mathrm{~min}$. Pelleted crude nuclei were resuspended in $0.075 \mathrm{M} \mathrm{NaCl}, 0.024 \mathrm{M} \mathrm{Na}$ EDTA (saline EDTA), pH 7.4. All the mammary glands were separated from the lymph nodes, pooled and minced. The minced tissue was then incubated in a solution of collagenase III $0.3 \%$ in phosphate-buffered saline (PBS; $10 \mathrm{ml} / \mathrm{g}$ of tiscue). To yield a cell pellet free of fat cells, the minced tissue was swirled on a gyratory water bath shaker at 150 r.p.m. at $37^{\circ} \mathrm{C}$ for $-90 \mathrm{~min}$ or until the suspension was uniform without any mecroscopic lumps. Tissue suspensions were centrifuged and washed with PBS. Pellets containing mammary epithelial and stromal cells were utilized for DNA damage evaluation (Moon et al., 1969; Yarg et al., 1980). 
Table I. General design of the experiments

Amount $(\mathrm{mg} / \mathrm{kg}$ body $\mathrm{wt})$ of agents administered at the given developmental stage

\begin{tabular}{|c|c|c|c|c|}
\hline Group number & PrenataP & Neonatal $^{\text {b }}$ & Young adult females & \\
\hline 1 & PB, 60 & - & - & DMBA, 80 \\
\hline 2 & - & PB, 60 & - & DMBA, 80 \\
\hline 3 & - & - & PB, 60 & DMBA, 80 \\
\hline 4 & $\mathrm{~PB}, 0.5$ in drinking water & - & - & DMBA, 80 \\
\hline 5 & $\mathrm{~PB}, 0.5$ in drinking water & - & PB, 60 & DMBA, 80 \\
\hline 6 & Ar, 100 & - & Ar, 500 & DMBA, 80 \\
\hline 7 & - & Ar, 100 & Ar, 500 & DMBA, 80 \\
\hline 8 & - & - & Ar, 500 & DMBA, 80 \\
\hline 9 & - & - & - & DMBA, 80 \\
\hline
\end{tabular}

Treatments were performed by i.g., except as indicated.

The agents were given from day 14 to 20 of gestation. Treatment with PB was performed once a day. Aroclor (Ar) was given on days $14,16,18$ and 20.

${ }^{b} \mathrm{~PB}$ was administered once a day on days 1 to 7 of age. Aroclor was given on days 1, 3, 5 and 7 of age.

'DMBA was given to 55-day-old Sprague-Dawley fermales. PB and aroctor were administered 24 and $72 \mathrm{~h}$ before DMBA exposure, respectively.

Table II. Modulating effects of PB on DNA damage induced in the liver and the mammary gland by DMBA given to 55-day-old Sprague-Dawley female rats

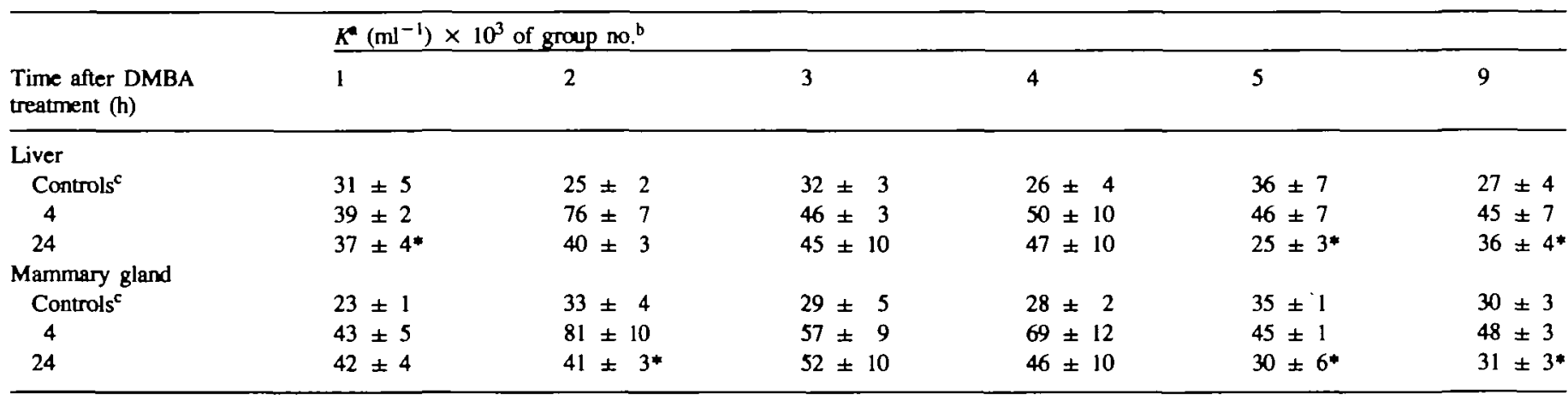

Mean \pm S.D. of a minimum of four experiments (8-12 determinations).

bTreatments of each experimental group are detailed in Table $\mathrm{I}$.

'These animals were exposed to the enzyme inducers but did not receive DMBA.

The values were significant at $P<0.005$ by the Mann-Whitney test. *Not significant.

\section{Alkaline elution of DNA}

DNA damage, as single-strand breaks or weak points in alkali, was measured by the alkaline elution technique (Bolognesi $e t$ al., 1985). Briefly, aliquots containing $0.5-1.0 \times 10^{6}$ nuclei were applied to membrane filters (Millipore Corp., USA; $25 \mathrm{~mm}$ diameter, $5 \mu \mathrm{m}$ pore size). Cnude nuclei on the filters were lysed at room temperature. Single-stranded DNA fractions were eluted with a solution containing $0.04 \mathrm{M}$ EDTA, tetra ethylammonium hydroxide (TEA 10\% in water) to provide a pH of 12.3. Fractions were collected at $6 \mathrm{~min}$ intervals for $1 \mathrm{~h}$ and the flow rate was $0.34 \mathrm{ml} / \mathrm{min}$. Fluorimetric determination of DNA was performed with 33258 Hoechst reagent according to the method developed in our laboratory (Cesarone et al., 1979). The results were expressed as elution rate constant $(K)$ :

$$
K\left(\mathrm{~m}^{-1}\right)=\frac{-\ln \text { fraction of DNA retained on the filter }}{\text { eluted volume }}
$$

The standard deviation and the non-parametric Mann-Whitney tests were used for the statistical analysis (Siegle, 1956).

\section{Results}

The mammary gland is a known target tissue for DMBA initiated carcinogenesis, while the liver is the most susceptible organ to DNA damaging agents and a major site of drug metabolism. Following a preliminary approach indicating that no DNA strand breaks are revealed when these organs were taken $2 \mathrm{~h}$ after treatment (values of $K$ were in the range of the untreated animals), we chose $4 \mathrm{~h}$ as the minimum interval sufficient to allow detection of a significant amount of DNA damage and $24 \mathrm{~h}$ as a period interval sufficient to measure persistence of the damage. The results are summarized in Tables II and III. A significant amount of DNA damage in the liver and the mammary gland of control females was observed $4 \mathrm{~h}$ after DMBA treatment with a value of $K$ of 45 and 48, respectively. At 24 h the damage disappeared and was similar to that found in the untreated animals.

Enzyme induction by $P B$ in different developmental stages

Pretreatment with PB generally caused an increase in DNA damage induced by DMBA in the liver and mammary gland compared to controls, both in terms of a raised elution rate and of its persistence in time. The extent and the time course of this enhanced effect was particularly significant when PB treatment was performed during neonatal life (group 2 in Table II and Figure $1 \mathrm{~A}$ and $\mathrm{B}$ ). In this instance the average elution constant, evaluated $4 \mathrm{~h}$ after DMBA treatment, was $\sim 2$-fold higher with respect to the values obtained in the same organs of the uninduced animals (in the liver it was 76 versus 45 and in the mammary gland it was 81 versus 48 , respectively).

When two different treatment modalities were adopted to expose prenatal animals to $\mathrm{PB}$ induction, it was shown that administration in drinking water was more effective compared to exposure by i.g. This was indicated by a statistically significant increase in DNA damage observed in the liver and mammary gland of the animals given the former treatment schedule and evaluated $4 \mathrm{~h}$ after treatment with DMBA (groups 1 and 4 in Table II). 
Table III. Modulating effects of aroclor on DNA damage induced in the liver and the mammary gland by DMBA given to 55-day-old Sprague-Dawley female rats

\begin{tabular}{|c|c|c|c|c|}
\hline \multirow[b]{2}{*}{$\begin{array}{l}\text { Time after DMBA } \\
\text { treatment }(\mathrm{h})\end{array}$} & \multicolumn{4}{|c|}{$K^{\circ}\left(\mathrm{ml}^{-1}\right) \times 10^{3}$ of group no. ${ }^{b}$} \\
\hline & 6 & 7 & 8 & 9 \\
\hline \multicolumn{5}{|l|}{ Liver } \\
\hline Controls $^{c}$ & $30 \pm 3$ & $28 \pm$ & $27 \pm 7$ & $27 \pm 7$ \\
\hline 4 & $50 \pm 3$ & $39 \pm 4$ & $45 \pm 7$ & $45 \pm 7$ \\
\hline 24 & $45 \pm 6$ & $34 \pm 6^{*}$ & $38 \pm 4$ & $36 \pm 4^{*}$ \\
\hline \multicolumn{5}{|l|}{ Mammary gland } \\
\hline Controls ${ }^{c}$ & $30 \pm 10$ & $32 \pm 10$ & $30 \pm 3$ & $30 \pm 3$ \\
\hline 4 & $52 \pm 10$ & $46 \pm 8$ & $45 \pm 8$ & $48 \pm 3$ \\
\hline 24 & $45 \pm 7$ & $37 \pm 3$ & $34 \pm 6^{*}$ & $31 \pm 3 *$ \\
\hline
\end{tabular}

"Mean \pm S.D. of a minimum of four experiments (8-12 determinations).

b Treatments of each experimental group are detailed in Table I.

'These animals were exposed to the enzyme inducers but did not receive DMBA.

The values were significant at $P<0.005$ by the Mann-Whitney test. "Not significant.

Following this result repeated enzyme induction was performed by giving $\mathrm{PB}$ in drinking water during pregnancy and by i.g. in 54-day-old female progeny. This schedule caused a decrease in the extent and persistence of DNA damage by DMBA, as shown by the comparison of groups 4 and 5 in Table II.

\section{Effects of enzyme induction by aroclor}

Aroclor was given to pregnant rats or newborn and a second exposure was given to 52-day-old females (groups 6 and 7, respectively). Other females were left intact and given aroclor at 52 days of age (group 8). These groups were then treated with DMBA on day 55. Under these experimental conditions there was no significant increase in DNA damage in the liver and mammary gland evaluated in the several treated and control groups. However, $24 \mathrm{~h}$ after DMBA treatment an increase in the persistence of DNA damage was observed in the liver and mammary gland of the animals of group 6 compared to those of group 9 ( $K$ in the liver was 45 versus 36 and 45 versus 31 respectively).

\section{Discussion}

Drug metabolizing activities appear late in pregnancy or immediately after birth and progressively increase during the first weeks of life (Gillette and Stripp, 1975; Doerjer et al., 1978; Pelkonen, 1980). Several factors have been suggested or recognized to influence the ontogenesis of these enzymatic activities (Pelkonen, 1980; Klinger, 1982). The complexity of the possible metabolic pathways of DMBA provides many opportunities for alteration of the balance between production of highly carcinogenic and mutagenic derivatives and of inert detoxified products.

Our results indicate that DNA damage kinetics caused by DMBA are modulated by previous treatment with PAH inducers, such as PB and aroclor, during prenatal and neonatal life. A pronounced increase in DNA damage was demonstrated after PB induction, while only a marginal increase was evident following treatment with aroclor. In both cases it may be hypothesized that a different ratio of cytochromes P448/P450 is induced, resulting in impaired or improved detoxification of DMBA.

There exists a peculiar immaturity of inactivating versus activating enzymes in perinatal life (Rice, 1979), a phenomenon

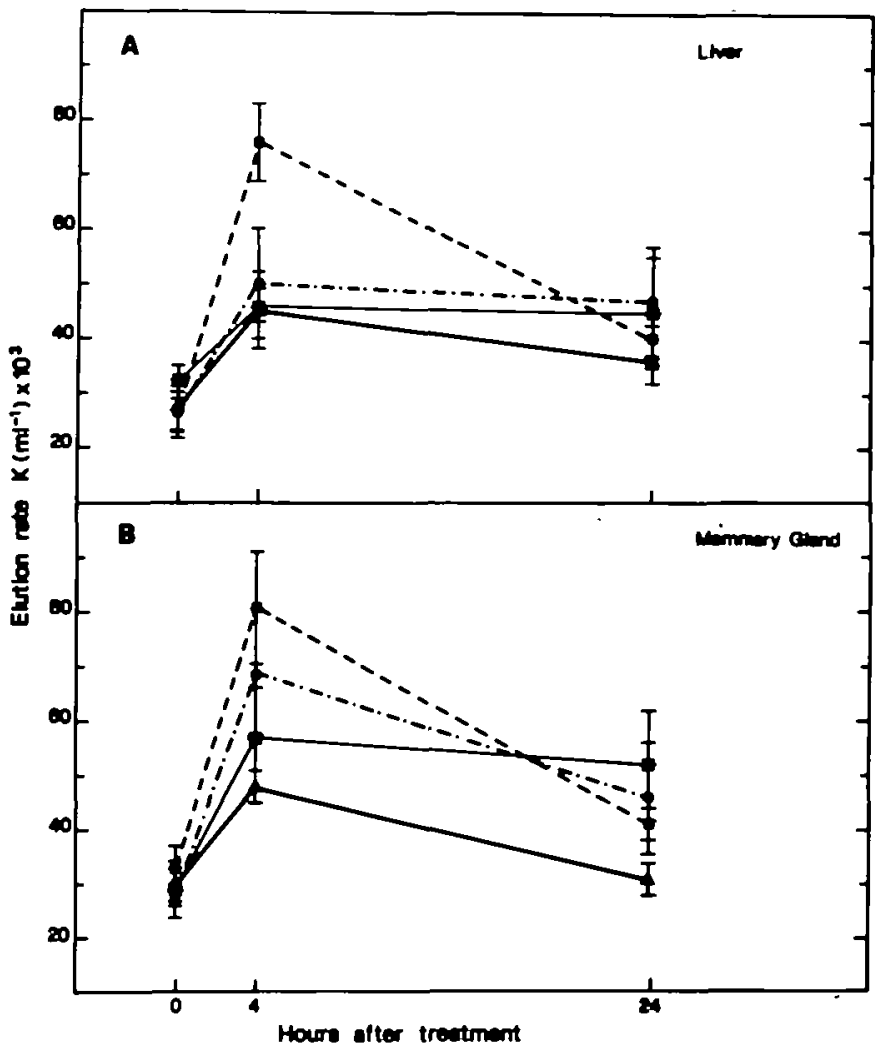

Fig. 1. Time-dependence of the elution constant in alkali of DNA from liver (panel A) and mammary gland (panet B) of young-adult Sprague-Dawley female rats treated with DMBA $(80 \mathrm{mg} / \mathrm{kg}$, i.g.). The animals were induced with PB $60 \mathrm{mg} / \mathrm{kg}$ i.g. in prenatal $(*-*)$, neonatal $\left(\square_{--\square}\right)$ and adult life $(\bullet-\cdot-\bullet)$ or uninduced $(\boldsymbol{\Delta}-\boldsymbol{\Delta})$.

that might explain our observation of the increased DNA damage by DMBA in young adult females exposed to PB in utero or during neonatal life. It appears that the induction of the enzyme system responsible for the metabolic activation of DMBA is more effective when it is performed in neonates compared to fetal and adult organisms, shown by the observation that DNA damage was increased by neonatal treatment with PB. These confirm previous reports that the neonatal period of development is critical to the maturation of microsomal enzymes (Pelkonen, 1980; MacDonald et al., 1981; Assael, 1982). Although it is believed that during pregnancy enzyme inducers are barely effective in inducing the microsomal enzyme system (Romano et al., 1983), at least one report has suggested an inductive effect in increasing metabolic activation of benzo[ $a$ ]pyrene during organogenesis (Bolognesi et al., 1985).

DMBA is considered a potent initiator of mammary tumorigenesis in rats. It is currently accepted that the binding of chemical carcinogens to DNA is an important early step in the carcinogenic process (Harvey, 1985). DNA binding and DNA adducts by DMBA metabolites have been studied in numerous cell systems in vitro (Sawicki et al., 1983; Singletary and Milner, 1986) and in vivo (Di Giovanni and Jachen, 1980; Cheng et al., 1988; Moore et al., 1988), where it was shown that the liver and the mammary gland are the primary target. The metabolism of DMBA to electrophilic ultimate carcinogens is assumed to be a prerequisite for initiation of its carcinogenic effects. The metabolic fate of a compound is a function of three processes occurring together (activation, deactivation and reactivation) whose dynamic interaction results in the local concentration and 
lifetime of the active metabolites. In this context it is interesting that repeated stimulation of the microsomal enzyme system by PB has resulted in a shorter persistence of DNA damage compared to controls. One could guess that the repeated enzymatic stimulation changes the metabolic pathway of DMBA in such a way that DNA adducts are efficiently repaired.

Modulation of the metabolic performance of xenobiotics has a great toxicologic relevance in terms of differential susceptibility to chemical carcinogens. Many environmental pollutants and drugs appear to be modifiers of enzymatic activities. Therefore the exposure of developing organisms to these agents during preand neonatal life could affect the individual susceptibility of adult progeny to different classes of chemical carcinogens.

\section{References}

Assael,B.M. (1982) Pharmacokinetics and drug distribution during postnatal development. Pharmacol. Ther., 18, 159.

Bolognesi,C., Rossi,L., Barbieri,O. and Santi,L. (1985) Benzo[alpyrene-induced DNA damage in mouse fetal tissues. Carcinogenesis, 6, 1091-1096.

Cesarone,C.F., Bolognesi,C. and Santi,L. (1979) Improved microfluorimetric DNA determination in biological material using 33258 Hoechst. Anal. Biochem. 100, 188- 197.

Cheng,S.C., Prakash,A.S., Pigot, M.A., Hilton,B.D., Lee,H., Harvey,R.G. and Dipple,A. (1988) A metabolite of the carcinogen 7,12-dimethylbenz[a]anthracene that reacts predominantly with adenine residues in DNA. Carcinogenesis, 9. $1721-1723$.

Dao,T.L. (1964) Carcinogenesis of mammary gland in rat. Prog. Exp. Tumor Res., 5, 157-216.

Dao,T.L. (1969) Mammary cancer intuction by 7,12-dimethylbenz[ $a$ ]anthracene: relation to age. Science, $165,810-811$.

Dao,T.L., Tonoka, Y. and Gawlek,D. (1964) Effect of polycyclic hydrocarbons on mammary homograft survival and tumorigenesis. J. Natl. Cancer Inst., 33, 963-970.

Di Giovanni,J. and Jachen,M.R. (1980) Biotransformation and bioactivation of 7,12-dimethylbenz[a]anthracene (7,12-DMBA). Drug Metabol. Rev., 11, $61-101$.

Doerjer,G., Diessuer,H., Bucheler,J. and Kleihurs,P. (1978) Reaction of 7,12-dimethylbenz[a]anthracene with DNA of fetal and maternal rat tissues in vivo. Int. J. Cancer, 22, 288-291.

Gillette,J.R. and Stripp,B. (1975) Pre- and postnatal enzyme capacity for drug metabolite production. Fedn. Proc., 34, 172.

Harvey, R.G. (ed.) (1985) Polycyclic Hydrocartons and Carcinogenesis. American Chemical Society, Washington, DC.

Huggins,C.B. (1979) Experimental Leukemia and Mammary Cancer, University of Chicago Press, Chicago, IL, pp. 73-98.

Huggins,C., Grand,L.C. and Brillantes,F.P. (1961) Mammary cancer induced by single feeding of polynuclear hydrocarbons and its suppression. Nature, $189,204-207$.

Huggins,C.B. and Fukunishi,R. (1962) Mammary and peritoneal tumors induced by intraperitoneal administration of 7,12-dimethylbenz[ $a$ ] anthracene in newborn and adult rats. Cancer Res., 11, 474-478.

Janss,D.H. and Ben,T.L. (1978) Age-related modification of 7,12-dimethylbenz[a]anthracene binding to rat mammary gland DNA.J. Natl. Cancer Inst., 60, 173-177.

Jefocate,C.R. (1983) Integration of xenobiotics metabolism in carcinogen activation and detoxification. In Caldwell,J. and Jekdsy, W.B. (ods), Biological Basis of Detaxification. Academic Press, New York, pp. 31-76.

Klinger, W. (1982) Biotransformation of drugs and other xenobiotics during postnatal development. Pharmacol. Ther., 16, 377-384.

MacDonald,M.G., Fasco,M.J. and Kaminsky,L.S. (1981) Development of the hepatic mixed-function oxidase system and its metabolism of warfarin in the perinatal rat. Dev. Phamacol. Ther., 3, 1.

Moon,R.C., Janss,D.H. and Young,S. (1969) Preparation of fat cell-' free' rat mammary gland. J. Histochem. Cytochem., 17, 182-186.

Moore,C.J., Tricomi,W.A. and Gould,M.N. (1988) Comparison of 7,12-dimethylbenzo $a$ ] anthracene metabolism and DNA binding in mammary epithelial cells from three rat strains with differing susceptibilities to mammary carcinogenesis. Carcinogenesis, 9, 2099-2102.

Nebert,D.W. and Gelboin,H.V. (1969) The in vivo and in vitro induction of aryl hydrocarbon hydroxylase in mrammalian cells of different species, tissues, strains and developmental and hormonal states. Arch. Biochem. Biophys., 134, 76-89.

Nebert,D.W. (1973) Use of fetal cell culture as an experimental system for predicting drug metabolism in the intact animals. Clin. Phamacal. Ther., 14, 693-699.
Pelkonen, O. (1980) Biotransformation of xenobiotics in the fetus. Pharmacol. Ther., 10, 261-281.

Rice J.M. (1979) Perinatal period and pregnancy: intervals of high risk for chemical carcinogens. Environ. Health Perspect, 29, 23-27.

Romano,M., Gazzonti,G., Clos,V., Assael,B.M., Maffei Facino,R. and Salmona,M. (1983) Perinatal development of styrene monooxygenase and epoxide hydrolase in rat liver microsomes and nuclei. Chem.-Biol. Inseract., 47, 213-222.

Russo.J., Saby,J., Isenberg,W.M. and Russo,I.H. (1977) Pathogenesis of mammary carcinomas induced in rats by 7,12-dimethylbenz[a]anthracene. $J$. Natl. Cancer Inst., 59, 435-445.

Sawicki,J.T., Mosctrel,R.C. and Dipple,A. (1983) Involverment of both syn- and anti-dihydrodiol epoxides in the binding of 7,12-dimethylbenz [a]anthracene to DNA in mouse embryo cell cultures. Cancer Res., 43, 3212-3218.

Siegle,B. (1956) Non-parametric Statistics for the Behavioral Sciences, McGrawHill, New York, pp. 116-127.

Singletary,K.W. and Milner,J.A. (1986) DNA binding and adduct formation of 7,12-dimethylbenz $[a]$ anthracene by rat mammary epithelial cell aggregates in vitro. Carcinogenesis, 7, 95-98.

Yang,J., Richards,J., Guzman, R., Imagawa,W. and Nandi,S. (1980) Sustained growth in primary culture of normal mammary epithelial cells embedded in collagen gels. Proc. Natl. Acad. Sci. USA, 77, 2088-2092.

Received on March 30, 1990; accepted Octaber 12, 1990 